\title{
Risk Management Of Shanghai Enterprises With Financial Derivatives
}

Eden S. H. Yu, (Email: efedenyu@ cityu.edu.hk), City University of Hong Kong

\begin{abstract}
Using a survey, this paper examines the practices of risk management using financial derivatives by enterprises in Shanghai. It is found that the use of financial derivatives by Shanghai enterprises is still at its infancy stage. Many enterprises focus on only one or two types of derivatives for managing their business risks. This may be attributed both to the government regulations against speculation and the underdevelopment of the derivative markets in China.
\end{abstract}

\section{Introduction}

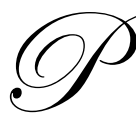

roviding the functions of "hedging", "speculative profit-making" and "price searching", the financial derivative markets have played an increasingly important role in the financial world since the beginning of the 1990s. The annual volume of global financial transactions has reached USD 150,000 billion. Enterprises are actively participating in the financial derivative markets either to minimize their own business risks or to speculate for profits. In China, financial derivative markets were once given the chance to develop. However, they failed to prosper due to various reasons and closed one after another.

Risks are a fact of life with enterprises and there are many methods for enterprises to manage these. ${ }^{1}$ One of the important methods is to use financial derivatives. ${ }^{2}$ Shanghai, as one of the advanced areas in reform and development in the 1990s, possesses certain advantages in the business of finance. Naturally, we are interested in understanding the practices of risk management of Shanghai enterprises using financial derivatives. This paper attempts to provide an answer to the query.

\section{The General Situation}

In order to have a basic understanding of the situation of Shanghai enterprises using financial derivatives, we randomly sampled 100 of them by telephone. Among these 100, $80 \%$ were local and $20 \%$ were using foreign investment (including joint ventures and co-operative enterprises). Moreover, $20 \%$ of them were small, and medium and large enterprises each had a $40 \%$ share respectively. The majority of these enterprises (73\%) were in the manufacturing industry. $17 \%$ of them were banks and foreign-trade enterprises, $5 \%$ were commercial, $3 \%$ were engaged in real estate, and $2 \%$ were in the service sector.

The results were quite disappointing. Only $3 \%$ of the enterprises took part in trading financial derivatives, $58 \%$ of them did not have any measure for risk management and $39 \%$ of them used internal-control to manage risks. On the inquiry about not using financial derivatives most of the enterprises stated that it was largely due to managerial policy (see Table 1).

However, this did not seem to reflect the actual situation of Shanghai enterprises using financial derivatives. Thus, we visited the Shanghai Branch of the State Administration of Foreign Exchange Control (SAFEC), and learned that at present in Shanghai, some large financial institutes were approved by the SAFEC to engage in the business of foreign exchange futures on commission. Exclusively foreign-invested enterprises, private enterprises and enterprises with trading backgrounds could entrust these financial institutes with "Licenses to Engage in the Business of Foreign Exchange Futures" on trading financial derivatives.

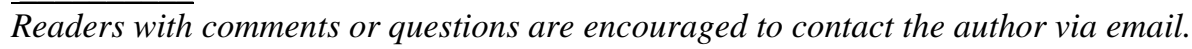


We then selected 30 enterprises in the business of foreign exchange futures and surveyed them by means of mail-questionnaires and interviews. There were 5 parts with 22 sub-questions in each of the questionnaires. The main theme of the questionnaires included: (a) the fundamental situation of Shanghai enterprises using financial deriva-

tives; (b) the practices of Shanghai enterprises using currency derivatives, interest rate derivatives and equity derivatives; and, (c) the control and reporting procedures of Shanghai enterprises. We received 12 effective and representative questionnaires of reasonable reliability in the end. To some extent, they reflected the current situation of risk management practices of Shanghai enterprises in relation to financial derivatives.

Table 1

The Reasons for Enterprises not Using Financial Derivatives

\begin{tabular}{|lc|}
\hline Reason for not using derivatives & Average Score \\
\hline Not familiar & 0.67 \\
Not necessary & 0.67 \\
Managerial policy & 2.50 \\
Cost greater than profit & 0.33 \\
Risky & 1.17 \\
\hline
\end{tabular}

(Note: The average score is 1 for the least important, 2 for the medium important and 3 for the most important.)

\section{The Survey Results}

The Fundamental Situation of Using Financial Derivatives

Some survey results are listed in Table 2, Table 3 and Table 4. From the survey, we see that $80 \%$ of the enterprises investigated needed to manage foreign exchange exposure and interest rate exposure, $60 \%$ of the enterprises needed to manage commodity exposure and equity market exposure. While most of them used forwards and swaps to manage foreign exchange exposure and interest rate exposure, futures were frequently used to manage commodity exposure and equity market exposure. The reason for enterprises using derivatives was primarily to hedge for contractual commitments. Besides, derivatives were also used to hedge for anticipated transactions and to reduce the cost of funds by means of market arbitrage.

In using derivatives, enterprises were greatly concerned about their pricing and valuing. Thus, the use of derivatives was still at its beginning stage even with those enterprises in the business of derivative trading. Their problems were the lack of knowledge about derivative usage, lack of comprehension about government policies, and the inadequacy of service providing institutes to take care of their interests. These taken altogether kept the use of derivatives with Shanghai enterprises at a fairly low level.

Table 2

The Types of Derivatives Used for the Management of Different Kinds of Exposures

\begin{tabular}{|lccccc|}
\hline & Forwards & Futures & Swaps & Options & $\begin{array}{c}\text { Structured } \\
\text { Derivatives }\end{array}$ \\
\hline Foreign Exchange Exposure & 3.8 & 1.4 & 3.4 & 1.6 & 0.6 \\
Interest Rate Exposure & 3.4 & 1.4 & 2.8 & 1.8 & 0.6 \\
Commodity Exposure & 1.4 & 1.8 & 0.6 & 0.8 & 0.2 \\
Equity Market Exposure & 0.6 & 2.0 & 0.4 & 1.6 & 0.2 \\
\hline
\end{tabular}

(Note: The average score is 1 for the least important and 5 for the most important.) 
Table 3

The Reasons for Enterprises Using Financial Derivatives

\begin{tabular}{|lc|}
\hline Reason for Using Derivatives & Average Score \\
\hline To Reduce Costs of Funds by Market Arbitrage & 1.4 \\
To Minimize Volatility in Accounting Profits & 0.6 \\
To Minimize Volatility in Cash Flows & 0.4 \\
To Hedge in the Balance Sheet & 0.0 \\
To Hedge for Contractual Commitments & 1.8 \\
To Hedge for Anticipated Transactions & 1.4 \\
To Hedge against Economic/Competitive Exposure & 1.0 \\
\hline
\end{tabular}

(Note: The average score is 0 for not applicable, 1 for the least important and 3 for the most important.)

Table 4

The Concerns of Enterprises Using Financial Derivatives

\begin{tabular}{|lc|}
\hline & Average Score \\
\hline Credit Risk & 0.6 \\
Uncertainty about Qualifying for Hedge & 0.0 \\
Accounting Procedure & 0.2 \\
Transaction Costs (Bankers' Fees) & 0.0 \\
Liquidity Risk & 0.0 \\
Lack of Knowledge about Financial Derivatives & 1.0 \\
Difficulty in Understanding the Firm's Exposures & 0.2 \\
Perceptions by Investors, Regulators, and the General Public & 0.6 \\
Pricing and Valuing Financial Derivatives & 2.4 \\
Monitoring and Evaluating Hedging Results & 0.8 \\
Evaluating the Risk of Proposed Derivative Transactions & 0.8 \\
\hline
\end{tabular}

(Note: The average score is 0 for not concerned, 1 for low, 2 for medium and 3 for high.)

The Situation on the Use of Currency Derivatives

The survey data listed in Table 5 to Table 8 show that enterprises frequently hedged for anticipated transactions within one year in the currency derivative market. This aligns with the situation we ascertained from several large banks. At present, those enterprises entrusting banks in the business of foreign exchange futures are mostly foreign trade enterprises. It is inevitable for them to encounter exchange rate risk. Making use of the banks' foreign exchange forward services can keep them safely away from this risk.

All enterprises paid considerable attention to their own exchange rate expectations. This causes them to take positions actively based on their own view of the market. As the time span of banks' foreign exchange futures business was not very long and usually not exceeding 4 months, this made $67 \%$ of the enterprises hold only foreign currency derivatives with a maturity of 90 days or less. Those foreign currency derivatives with a maturity of over one year were extremely rare. All enterprises regarded the management of risks due to contractual commitments or repatriations, and those due to anticipated transactions within 1 year, to be the top priorities. Most of them used foreign exchange forwards for the risk management. This obviously has something to do with the present situation in that banks provide a service only for foreign exchange forwards.

Table 5

The Frequency of Hedging Transactions of Enterprises in the Currency Derivative Markets

\begin{tabular}{|lc|}
\hline & Average Score \\
\hline Foreign Repatriations & 1.00 \\
Contractual Commitments & 2.00 \\
Anticipated Transactions within One Year & 2.75 \\
Anticipated Transactions over One Year & 1.00 \\
Competitive Economic Exposure & 1.50 \\
Translation of Foreign Accounting Statements & 1.25 \\
\hline
\end{tabular}

(Note: The average score is 0 for not applicable, 1 for never, 2 for sometimes and 3 for frequently.) 
Table 6

The Frequency of Enterprises Taking Actions Based on their Exchange Rate Anticipation

\begin{tabular}{|lc|}
\hline & Average Score \\
\hline Altering the Timing of Hedges & 1.75 \\
Altering the Size of Hedges & 2.00 \\
Actively Taking Positions & $\mathbf{2 . 2 5}$ \\
\hline
\end{tabular}

(Note: The average score is 0 for not applicable, 1 for never, 2 for sometimes and 3 for frequently.)

Table 7

The Maturity Distribution of Foreign Currency Derivatives Held by the Enterprises
\begin{tabular}{|lc|}
\hline Maturity & Percent \\
\hline 90 Days or Less & $67 \%$ \\
91 to 180 Days & $10 \%$ \\
Until the End of the Current Fiscal Year & $10 \%$ \\
One to Three Years & $\mathbf{6 . 5 \%}$ \\
Over Three Years & $\mathbf{6 . 5 \%}$ \\
\hline
\end{tabular}

Table 8

The Derivatives Used for Specific Kinds of Exposures

\begin{tabular}{|lccccc|}
\hline & Forwards & Futures & Swaps & Options & $\begin{array}{c}\text { Structured } \\
\text { Derivatives }\end{array}$ \\
\hline To Manage Contractual Commitments / Repatriations & & 3.50 & 1.50 & 4.00 & 1.75 \\
For Anticipated Transactions within 1 Year & 4.50 & 2.00 & 3.75 & 1.50 & 1.50 \\
For Anticipated Transactions over 1 Year & 4.67 & 2.00 & 3.33 & 2.67 & 1.75 \\
To Manage Economic / Competitive Exposure & 4.50 & 2.00 & 3.50 & 2.00 & 2.33 \\
Translation of Accounts & 3.00 & 2.50 & 3.50 & 3.00 & 3.00 \\
\hline
\end{tabular}

(Note: The average score is 1 for the least important and 5 for the most important.)

The Situation on the Use of Interest Rate Derivatives

Table 9 and Table 10 describe the situation on the use of interest rate derivatives. Enterprises often traded in the interest rate derivatives market for swapping floating rate debts with fixed rate debts and for reducing costs or locking-in rates based upon a market expectation. They frequently altered the timing of hedges according to their expectations of market interest rates. Since the 1995 experience in China, interest rate derivatives have rarely been used. Among the surveyed enterprises, only financial institutes and large foreign invested enterprises used more of them. Enterprises in other businesses seldom or never did so.

Table 9

The Frequency of Transaction of Enterprises in the Interest Rate Derivative Market

\begin{tabular}{|lc|}
\hline & Average Score \\
\hline Swap Existing Fixed Rate Debts with Floating Rate Debts & 2.00 \\
Swap Floating Rate Debts with Fixed Rate Debts & 2.50 \\
Fix in Advance New Debts (and Interest Rate) & 1.50 \\
Reduce Costs or Lock-In Rates Based upon a Market View & 2.25 \\
\hline
\end{tabular}

(Note: The average score is 0 for not applicable, 1 for never, 2 for sometimes and 3 for frequently.)

Table 10

The Frequency of Enterprises Taking Actions Based on Their Market View of Interest Rates

\begin{tabular}{|lc|}
\hline & Average Score \\
\hline Altering the Timing of Hedges & 2.67 \\
Altering the Size of Hedges & 2.00 \\
Actively Taking Positions & $\mathbf{1 . 6 7}$ \\
\hline
\end{tabular}


(Note: The average score is 0 for not applicable, 1 for never, 2 for sometimes and 3 for frequently.)

The Situation on the Use of Equity Derivatives

There is no equity derivative in China at the moment. The Committee of Security Supervision and Administration promulgated a decree last year forbidding funds of enterprises and banks to participate in stock markets. Thus, at present, none of the Shanghai enterprises uses equity derivatives. However, from the questionnaires received, we see that $20 \%$ of the enterprises intended to use equity derivatives for the management of the tax and accounting consequences of an equity position and the management of pension funds and other assets (see Table 11).

Table 11

The Situation of the Use of Equity Derivatives

\begin{tabular}{|lc|}
\hline & Average Score \\
\hline Using Put Options for Share Repurchase Programmes & 1.5 \\
Profit-Taking on Existing Options & 1.5 \\
Hedging Stocks Acquired during Mergers & 3.5 \\
Managing the Tax and Accounting Consequences of an Equity Position & 4.0 \\
Management of Pension funds and Other Assets & 4.5 \\
\hline
\end{tabular}

(Note: The average score is 1 for the least important and 5 for the most important.)

\section{The Controlling and Reporting Procedures of Enterprises}

The combined result of our survey and interview revealed that all the enterprises would consider the grade of trustworthiness of their counterparts when using financial derivatives. Among them, $40 \%$ chose those with AAA grades, $20 \%$ chose those with AA grades and another $20 \%$ chose those with an A grade. The other $20 \%$ of enterprises did not have any set policy, but considered the grade of trustworthiness of their counterparts must be at least A. As the grades of trustworthiness of the enterprises' counterparts were all very high, none of them had ever experienced default from their counterparts on derivative contracts.

When managing their derivative activities, $60 \%$ of the enterprises used self-developed systems and $40 \%$ of them used software purchased from a third party. Enterprises trusted their in-house software most, followed by their dealers, for the valuation of derivative positions and the priority of importance of the derivatives (see Table 12). When evaluating the riskiness of specific derivative transactions or portfolios, most enterprises used stress testing or scenario analysis and the "value at risk" approach (see Table 13).

Among those surveyed enterprises, $75 \%$ of them had documented policies with respect to the use of derivatives. The executives in charge of derivative transactions of $80 \%$ of these enterprises had the power over derivative trading decisions. All derivative activities were reported to the supervisory executives and the directors of the enterprises. There were very frequent reports being administered. $50 \%$ of these enterprises had them once a month, $10 \%$ had them twice a month, and $40 \%$ had them on a daily basis. Moreover, $60 \%$ of the enterprises considered their philosophy for managing derivative positions to be best described "as an isolated business for some objectives and as individual transactions associated with specific exposures for other objectives" (see Table 14).

Table 12

The Reliability of Various Sources on Risk Management of Enterprises

\begin{tabular}{|lc|}
\hline & Average Score \\
\hline Dealer from/to Whom the Derivatives were Bought/Sold & 1.25 \\
Other Derivative Dealers & 0.25 \\
Market Quoting Services & 1.00 \\
Accounting Firms & 1.00 \\
Consulting Firms & 0.25 \\
Firms' In-House Software & 2.25 \\
\hline
\end{tabular}

(Note: The average score is 1 for the least reliable, 2 for the more reliable and 3 for the most reliable.) 
Table 13

The Popularity of Different Evaluation Approaches

\begin{tabular}{|lc|}
\hline Evaluation Method & Percent \\
\hline "Value at Risk" & $75 \%$ \\
Stress Testing or Scenario Analysis & $100 \%$ \\
Option Sensitivity Measures (Delta, Gamma, Vega, ...) & $50 \%$ \\
Price Value of a Basis Point (Value of an 01) or Duration & $50 \%$ \\
\hline
\end{tabular}

Table 14

The Philosophy of Enterprises Managing their Derivative Positions

\begin{tabular}{|lc|}
\hline & Percent \\
\hline Individual Derivative Transactions Associated with Specific Corporate Exposures & $20 \%$ \\
As a Business Associated with Aggregate Corporate Exposures & $20 \%$ \\
As an Isolated Business & $0 \%$ \\
As an Isolated Business for Some Objectives and as Individual Transactions & $60 \%$ \\
Associated with Specific Exposures for Other Objectives & \\
\hline
\end{tabular}

The Survey about the Jiangsu Branch of the Bank of China

From our interview, we learned that the Jiangsu Branch of the Bank of China did competent work in the business of derivatives. This was especially so during the South-East Asian financial crisis in 1997, when the bank helped nearly 100 enterprises in the Jiangsu province to avoid foreign exchange rate risks and increase their chance of transactions. Thus, this business was nicknamed "the amulet" of exports and imports by the foreign trading enterprises.

From the information we obtained, the Jiangsu Branch of the Bank of China began its business of forward settlement and selling of foreign exchanges in April 1997. Until the present, 443 transactions have been handled, with a volume of trade of USD162 million. Altogether, they have raised the foreign exchange settlement income of the enterprises by RMB5 million. As more and more foreign trading enterprises have realized the benefits of this business, its development has been like driving on the "expressway". In the first two months of this year alone, 143 transactions were recorded with a volume of trade of USD58 million, equivalent to $50.9 \%$ and $55.8 \%$ of the whole year of 1997 respectively. Both the amount of a single transaction and the average daily volume of trade have shown a remarkably rising trend.

At present, this bank is promoting the business in the entire province and in the meantime emphasizes the development of core product, core area, core industry and core clientele. The business of forward settlement and selling of foreign exchanges was set as the core development product of this year and would become a new impetus of economic growth with the bank. It was expected that the total transaction amount of the year would reach USD1 billion, accounting for about $10 \%$ of the bank's total amount of the business of settlement and selling of foreign exchanges.

\section{The Findings in the Survey}

Summarizing our survey data, we found:

(a) A Rising Trend in Enterprises' Demand for Financial Derivatives

It is inevitable for those enterprises possessing foreign exchanges, whether of their own accord or through self-raising, and those enterprises engaged in the business of exports and imports, to encounter the problem of exchange rate fluctuation. However, only a few of these enterprises were aware of this exchange rate risk, let alone those that would actively use derivatives to minimize their exchange rate risks. The financial crisis that happened in South-East Asia over the last few years raised an alarm for all these enterprises, which consequently increased their awareness of the unpredictability of the international foreign exchange market and the risks they were involved in. In addition, several large banks have been putting considerable effort into advertising the importance of financial 
derivatives and the related business training recently. All these have attracted an increasing number of enterprises to use financial derivatives to manage risks. It has also made the enterprises' demand for banks' derivative products assume an obvious rising trend since the beginning of this year.

(b) Enterprises being Novice but Good Self-Regulatory Derivative Users

Our survey showed that the use of derivatives among enterprises was still in its infancy. Very frequently, they used only a single kind of derivatives for their risk management. On one hand, it was because enterprises lacked the knowledge about derivatives and there was no servicing institution to advise them. On the other hand, financial institutes were only able to provide a few kinds of derivatives for enterprises; thus, the choices of selection were comparatively limited.

All enterprises did well on their own self-regulation. It might be due to the lessons they drew from the bankruptcy of the Bahrain Bank in England. Most enterprises, especially financial institutes, had extensive written rules and regulations as well as internal rules for derivative operations. To a large extent, all these helped to minimize the operational risks of derivative transactions.

(c) The Immature Brokerage Services of Derivatives of Financial Institutes Requiring Continuous Improvement and Further Market Development

Whereas some financial institutes had been in the business of derivative trading for nearly 6 years, some others had only engaged in it recently. Thus, it was unavoidable for them to suffer from a narrow business scope and the small variety of their services. For instance, many enterprises considered that the business of forward settlement and selling of foreign exchange would make cost accounting and risk reduction easy for them. They were willing to continue this business. However, even though there were nine different derivatives with various lengths of maturity, the longest maturity period did not exceed four months. The demand for long-maturity derivative products of some enterprises could not be met.

Moreover, there was still scope for service improvement of all the financial institutions. Such improvement was expected to be carried out steadily during their future operations. Since derivative trading in China was still in its infancy and the market was still immature, a constant improvement of the financial institutions and an active market development plan were much in need.

\section{Suggestions for Future Research}

Further to this paper, we are currently studying the situation of risk management practices with companies in Hong Kong. A similar survey is being conducted. It would be interesting to know the similarities and differences of risk management practices of enterprises sharing the same culture but with different economic and political backgrounds. We hope that a formal comparison of risk management practices of enterprises between the two cities may be carried out once we have collected sufficient data for the analysis.

The research underlying this study was supported by the Research Grants Council Competitive Earmarked Project (Project \# CUHK 4106/97H). This paper was completed while the author was a faculty member at The Chinese University of Hong Kong. Dr. Louis Yau and Dr. Chen Xian provided able assistance. The author is solely responsible for any remaining shortcomings.

\section{Endnotes}

1. It is generally agreed that risk management is a continuous process. The procedures and steps towards good risk management, which include objective determination, risk identification, risk evaluation, decision on alternative risk treatment and management review and evaluation, should be carried out over and over again, see for example, Bannister and Bawcutt (1981), Campbell and Kracaw (1993), Doherty (1985), Jorion and Khoury (1996) and Vaughan (1997). For an introductory text on risk management, see Crockford (1986).

2. Financial risks are often managed by the method of insurance in the name of hedging, see for example Howcroft and Storey (1989) and Morgan, Andersen and Financial Engineering Ltd. (1997). 


\section{References}

1. $\quad$ Bannister, J. E. and P. A. Bawcutt, Practical Risk Management, Witherby, 1981.

2. Campbell, Tim S. and William A. Kracaw, Financial Risk Management: Fixed Income and Foreign Exchange, HarperCollins, 1993.

3. Crockford, Neil, An Introduction to Risk Management, Woodhead-Faulkner, 1986, 2nd edition.

4. Doherty, Neil A., Corporate Risk Management: A Financial Exposition, McGraw-Hill, 1985.

5. Howcroft, Barry and Christopher Storey, Management and Control of Currency and Interest Rate Risk, Woodhead-Faulkner, 1989.

6. J. P. Morgan \& Co. Inc., Arthur Andersen LLP, and Financial Engineering Ltd., The J. P. Morgan/Arthur Andersen Guide to Corporate Risk Management, Risk Publications, 1997.

7. Jorion, Philippe and Sarkis J. Khoury, Financial Risk Management: Domestic and International Dimensions, Blackwell, 1996.

8. Vaughan, Emmett J., Risk Management, John Wiley \& Sons, Inc., 1997. 